\title{
Association Between Exposure To Air Pollutants and The Risk of Inflammatory Bowel Diseases Visits
}

\section{Siwen Ding}

Anhui Medical University

\section{Shu Sun}

Anhui Medical University

\section{Rui Ding}

Anhui Medical University

\section{Shasha Song}

Second Affiliated Hospital of anhui medical university

\section{Yi Cao}

Second Affiliated Hospital of anhui Medical College: Lanzhou University Second Hospital

\section{Lijiu Zhang ( $\sim$ zhanglijiu6336@163.com )}

Second Affiliated Hospital of Anhui Medical University

\section{Research Article}

Keywords: inflammatory bowel diseases, Air pollution, PM2.5, 03, CO, Distributed lag nonlinear model, Time series study

Posted Date: August 4th, 2021

DOl: https://doi.org/10.21203/rs.3.rs-705178/v1

License: (c) (1) This work is licensed under a Creative Commons Attribution 4.0 International License. Read Full License

Version of Record: A version of this preprint was published at Environmental Science and Pollution Research on October 20th, 2021. See the published version at https://doi.org/10.1007/s11356-02117009-0. 


\section{Abstract \\ Background}

The topic of inflammatory bowel disease (IBD) has attracted more and more attentions. Accumulating evidence suggests that exposure to air pollutants is associated with IBD, yet the results are inconsistent and study about daily exposure is few. This study evaluated the association between daily air pollution and IBD in Hefei, China.

\section{Methods}

Daily IBD admission data were obtained from two hospitals in Hefei from January 1, 2019 to December 31, 2019. Daily concentrations of major air pollutants were provided by the Hefei Environmental Protection Bureau. Meteorological data were collected from China Meteorological Data Network. Distributed lag nonlinear model (DLNM) considering both the lag effects of exposure factors and nonlinear relationship of exposure-reaction was used to assess the effect of daily air pollutants exposure on IBD admission.

\section{Results}

During the study period, totally 886 cases of IBD were recruited, including 313 cases of ulcerative colitis (UC) and 573 cases of Crohn's disease (CD). The findings showed $\mathrm{PM}_{2.5}, \mathrm{O}_{3}$ and $\mathrm{CO}$ exposure significantly increased the risk of IBD. Mean concentrations of $\mathrm{PM}_{2.5}, \mathrm{O}_{3}$ and $\mathrm{CO}$ in Hefei were $43.85 \mathrm{ug} / \mathrm{m}^{3}, 100.78 \mathrm{ug} / \mathrm{m}^{3}$, and $0.76 \mathrm{mg} / \mathrm{m}^{3}$, respectively. Each increase of $10 \mathrm{mg} / \mathrm{m}^{3}$ in $\mathrm{PM}_{2.5} / \mathrm{O}_{3}$ and $0.1 \mathrm{mg} / \mathrm{m}^{3}$ in $\mathrm{CO}$ increased the risk of IBD. The strongest effects of these three pollutants on IBD were observed in lag2-lag3 ( $R R=1.037,95 \% \mathrm{Cl}: 1.005-1.070 \%)$, lag3 ( $\mathrm{RR}=1.020,95 \% \mathrm{Cl}: 1.002-1.038 \%)$ and lag2 ( $\mathrm{RR}=1.036,95 \% \mathrm{Cl}: 1.003-1.071 \%$ ), respectively. In warm seasons, $\mathrm{PM}_{2.5}, \mathrm{O}_{3}$ and $\mathrm{CO}$ had a stronger effect increased the risk of IBD, which were observed in lag2 ( $R R=1.104,95 \% \mathrm{Cl}: 1.032-1.181 \%)$, lag2 and lag5 ( $\mathrm{RR}=1.023,95 \% \mathrm{Cl}: 1.002-1.044 \% ; \mathrm{RR}=1.036,95 \% \mathrm{Cl}: 1.004-1.069 \%)$ and lag2 $(\mathrm{RR}=1.071$, 95\% Cl: 1.012-1.133\%), respectively.

\section{Conclusions}

Air pollutants $\left(\mathrm{PM}_{2.5}, \mathrm{O}_{3}\right.$ and $\left.\mathrm{CO}\right)$ exposure could increase the risk of IBD, while the most susceptibility seasons for the exposure were mainly in warm seasons. This study contributes to the knowledge of the association between air pollution and IBD, but the associations need to be verified by further studies.

\section{Introduction}


Inflammatory bowel diseases (IBD) are disabling intestinal condition of unclear etiology, including Crohn's disease (CD) and ulcerative colitis (UC) (Chen et al. 2020), of which the symptoms can be characterized as intermittent recurrence and quiescent inflammatory remission (Sairenji et al. 2017). While the incidence of IBD has steadily increased in the Western world during the 20th century, IBD is relatively rare in developing countries (Bernstein et al. 2019). However, in the last few decades, the emergence of IBD has been recorded in newly industrialized countries in Asia, South America, and the Middle East. In the 21 st century, the incidence of IBD is increasing in almost all industrialized countries, with the incidence rates of $C D$ and $U C$ vary between $0.1-11$ and $0.5-24.5$ per 100,000 people, respectively, in different geographical regions of the world (Kaplan 2015). As a disease occurs during the most productive time of life and with severe complications, IBD imposes a heavy economic burden on both the families of patients and the society (Flynn and Eisenstein 2019).

The pathogeneses of IBD are still unclear to date. Previous studies have reported that changes in diet, antibiotic use, hygiene status, microbial exposures and air pollution are all linked to IBD risk and progression (Ananthakrishnan et al. 2018). Accumulating studies in recent years have shown that outdoor air pollution, a serious public health challenge and affected populations all over the world (Brugha and Grigg 2014), could be a risk factor of IBD. In Wisconsin, USA, an ecological analysis correlated emissions with the number of hospitalizations for IBD by regional code and found a direct correlation between air pollutant emissions and the number of adult IBD hospitalizations (Ananthakrishnan et al. 2011). Analysis of individual pollutants showed statistically significant associations of IBD with carbon monoxide (CO), carbon dioxide $\left(\mathrm{NO}_{2}\right)$, sulfur dioxide $\left(\mathrm{SO}_{2}\right)$ and particulate matter with aerodynamic equivalent diameter $<2.5 \mu \mathrm{m}\left(\mathrm{PM}_{2.5}\right)$ (Ananthakrishnan et al. 2011). Exposure of the gut to air pollutants can occur via inhalation of gaseous pollutants, mucociliary clearance of particulate matter (PM) from the lungs and contamination of food and water sources (Ananthakrishnan et al. 2011). Short-term exposure of the gut to high levels of airborne PM results in increased gut permeability and heightened innate immune response in the small intestine, while chronic exposure results in increased expression of proinflammatory cytokines, alterations in microbiota composition, and function in the colon, eventually induces acute and chronic inflammatory responses in the gut (Kish et al. 2013). Exposure to oxidized pollutants, such as $\mathrm{SO}_{2}$ and $\mathrm{NO}_{2}$, also presented different impact on the risk of IBD (Kaplan et al. 2010). Oxidative pollutants, as oxidants, may cause oxidative stress in the system (Sies 1997). Accumulating data from experimental models and clinical studies indicate that oxidative stress signaling pathways are involved in the occurrence and development of IBD through multiple levels of function. Oxidative stress causes damage to the gastrointestinal mucosa and bacterial invasion, which in turn stimulates the immune response and triggers IBD (Goyette et al. 2007). Therefore, it is urgent to perform more epidemiological studies in developing countries to assess the association between air pollution exposure and IBD risk.

To date, few studies used time-series studies to assess statistical association between $\mathrm{PM}_{2.5}$, ozone $\left(\mathrm{O}_{3}\right)$ and $\mathrm{CO}$ exposure, lag effect, and the risk of IBD. Therefore, this study aimed to explore whether daily 
exposure to $\mathrm{PM}_{2.5}, \mathrm{O}_{3}$ and $\mathrm{CO}$ were linked with the risk of IBD visits in Hefei and evaluate the effects of seasonal variation and disease types.

\section{Materials And Methods}

\subsection{Study location and hospitalization data of IBD}

Hefei $\left(31.87^{\circ} \mathrm{N}, 117.28^{\circ} \mathrm{E}\right)$ is the capital city of Anhui province which has a population of 5.03 million and an area of $7056 \mathrm{~km}^{2}$. Hefei, as the economic, financial, cultural, and educational center of this province and the locale of this study, has been facing the problem of air pollution due to the rapid growth in the number of residents and vehicles in the past few years.

The data of the IBD patients were obtained from The First Affiliated Hospital of Anhui Medical University and The Second Affiliated Hospital of Anhui Medical University (from January 1, 2019 to December 31, 2019) in Hefei. The study only included patients living in the urban district of Hefei from January 1, 2019 to December 31, 2019, according to registered address. The IBD cases was diagnosed according to the Consensus on Diagnosis and Treatment of Inflammatory Bowel Disease (IBD) formulated by the Inflammatory Gastroenterology Group of the Chinese Society of Gastroenterology, published in Chinese Journal of Gastroenterology in 2018. We collected the medical information of all IBD cases from January 1, 2019 to December 31, 2019, which including age, gender, home address, clinic date, and the results of auxiliary examination.

\subsection{Air pollution and meteorological data}

We estimated the association between IBD visits and major ambient air pollutants with the consideration of the influence of meteorological factors. The daily concentrations of major air pollutants in the study period were provided by the Hefei Environmental Protection Bureau (HEPB), based on the average of ten air monitoring stations in Hefei. Daily meteorological factors were obtained from China Meteorological Data Network (http://data.cma.gov.cn). These data included the average temperature $\left({ }^{\circ} \mathrm{C}\right)$, average air humidity $(\%)$, average air pressure $(\mathrm{kPa})$, average wind speed $(\mathrm{m} / \mathrm{s})$, and average precipitation $(\mathrm{mm})$. The individual exposure level of cases was measured by the average of ten monitoring stations. The pollutants included particulate matter with aerodynamic equivalent diameter $<10 \mu \mathrm{m}\left(\mathrm{PM}_{10}\right), \mathrm{PM}_{2.5}, \mathrm{O}_{3}$, $\mathrm{CO}, \mathrm{NO}_{2}$, and $\mathrm{SO}_{2}, \mathrm{PM}_{10}, \mathrm{PM}_{2.5}, \mathrm{CO}, \mathrm{NO}_{2}$ and $\mathrm{SO}_{2}$ were 24-hour average concentration; $\mathrm{O}_{3}$ was $8 \mathrm{~h}$ maximum average concentration. The concentrations of the pollutants were all expressed as $\mu \mathrm{g} / \mathrm{m}^{3}$ except for $\mathrm{CO}$, which was presented as $\mathrm{mg} / \mathrm{m}^{3}$.

\subsection{Statistical analysis}

Spearman rank correlation analysis was performed to assess the correlations among major air pollutants, meteorological factors, and the daily admissions for IBD. The daily reports of IBD admissions are generally regarded as rare events, which follow a Poisson distribution approximately. Previous studies have demonstrated that there is a non-linear relationship between major air pollutants and health 
outcomes (Chun et al. 2020; Khreis et al. 2017). Therefore, we used the distributed lag nonlinear model (DLNM) based on the Poisson generalized linear model to assess the relationship between major air pollutants concentrations and IBD admission (Bernal et al. 2017; Gasparrini 2014). In this study, we established two models to evaluate the effects of major air pollutants concentrations change metrics, respectively.

First, we established a preliminary model without air pollutants. Since the purpose of this study was to assess the impact of short-term exposure of air pollution on the IBD visits, we adopt a natural cubic spline (ns) function to control the meteorological factors, seasonal variation, and long-term trends (Bhaskaran et al. 2013). "Time" variable (from 1 to 365 days) was used to control the long-term trends and seasonal variation with a 7* "years" degree of freedom (Kim and Lee 2019). Five meteorological factors including mean temperature $\left({ }^{\circ} \mathrm{C}\right)$, air humidity $(\%)$, air pressure $(\mathrm{kPa})$, wind speed $(\mathrm{m} / \mathrm{s})$, and precipitation $(\mathrm{mm})$ were also controlled by ns function with 3 degrees of freedom (Cheng et al. 2019).

Second, we established cross-basis functions to explore exposure-lag-response bidimensional relationships. We adopt a linear and a natural cubic spline (ns) function to fit the exposure-response relationship and the lag-response relationship, respectively (Huang et al. 2020). As for the lag days, we established a cross-basis function for each pollutant and set the initial maximum lag to 5 days (Huang et al. 2020). Finally, the single-pollutant model was as follows:

$Y_{t} \sim$ Poisson $\left(\mu_{t}\right)$

$\log \left(\mu_{t}\right)=a+\beta X_{t}+n s($ time, $d f)+n s\left(Z_{t}, d f\right)$

In this formula, $t$ is the day of the observation; $Y_{t}$ denotes the number of IBD visits on day $t ; \mu_{t}$ is the expected mean of $Y_{t} ; a$ is the interception; $\beta$ is the regression coefficient for each air pollutants; $X_{t}$ is pollutant concentrations at day $\mathrm{t}$; $\mathrm{ns}$ is a natural smoothing function for nonlinear variables; $\mathrm{df}$ is the degree of freedom; $Z_{t}$ is meteorological data on day $t$ (Cheng et al. 2019).

We used relative risk (RR) estimates and 95\% confidence interval $(\mathrm{Cl})$ to represent the lag-specific of IBD visits $10 \mu \mathrm{g} / \mathrm{m}^{3}$ increase in $\mathrm{PM}_{2.5}$ and $\mathrm{O}_{3}$, and per $0.1 \mathrm{mg} / \mathrm{m}^{3}$ increase in CO. Besides, stratified analyses were conducted by IBD classification (ulcerative colitis and Crohn's disease), and season (warm and cold) to assess the effects of air pollutants exposure. According to the geographical location and climate type of Hefei, we defined the warm season from April to September and the cold season from October to March of the next year.

Sensitivity analysis was also performed to identify the robustness of the results by changing the degrees of freedom (5-9 df) in the ns function of time.

The data were organized and the database was established by Microsoft Excel software; SPSS 23.0 software was used for general description and chi-square test. R 3.2.3 software was used for the regression analysis of Distributed lag nonlinear model. $\mathrm{P}<0.05$ was considered statistically significant. 


\section{Results}

\subsection{Descriptive results}

The characteristics of IBD cases, major ambient air pollutants and meteorological factors in this study are presented in Table 1. The daily mean concentration of $\mathrm{PM}_{2.5}$ was $43.85 \mu \mathrm{g} / \mathrm{m}^{3}\left(5-166 \mu \mathrm{g} / \mathrm{m}^{3}\right)$, $100.78 \mu \mathrm{g} / \mathrm{m}^{3}$ for $\mathrm{NO}_{2}\left(4-220 \mu \mathrm{g} / \mathrm{m}^{3}\right)$, and $0.76 \mathrm{mg} / \mathrm{m}^{3}$ for $\mathrm{CO}\left(0.3-1.7 \mathrm{mg} / \mathrm{m}^{3}\right)$. Daily mean values of temperature, relative humidity, air pressure, wind speed and precipitation were $16.34^{\circ} \mathrm{C}, 78.17 \%$, $100.96 \mathrm{kPa}, 2.26 \mathrm{~m} / \mathrm{s}$ and $1.59 \mathrm{~mm}$, respectively. Among the 886 IBD cases included, 313 were with ulcerative colitis, and 573 were with Crohn's disease. Five hundred and eight and 378 cases occurred in warm and cold seasons, respectively. Figure 1 presents the time series of air pollutants in Hefei, China during January 1, 2019 to December 31, 2019. The daily concentration of $\mathrm{PM}_{2.5}, \mathrm{O}_{3}$, and $\mathrm{CO}$ peaked in February 2019, May 2019 and January 2019 across the study period, respectively.

\subsection{The correlation of air pollutants and meteorological factors}

Table 2 shows that major air pollutants were significantly associated with each other. $\mathrm{PM}_{2.5}$ and $\mathrm{PM}_{10}$ were strongly and positively correlated to other pollutants except for $\mathrm{O}_{3}$. Among which $\mathrm{PM}_{2.5}$ and $\mathrm{CO}$ had the strongest correlation $(r=0.809), O_{3}$ were weakly and negatively correlated to other pollutants ( $r$ ranged from -0.287 to 0.090 ). The correlations among meteorological factors were weak except for air pressure and temperature $(r=-0.903)$. In addition, the correlation between meteorological factors and pollutants were low or moderate.

\subsection{The effects of air pollution exposure on the risk of IBD visits}

\subsection{1. $P M_{2.5}$ effects}

As shown in Fig. 2 and Fig. 3 , per $10 \mu \mathrm{g} / \mathrm{m}^{3}$ increase in $\mathrm{PM}_{2.5}$ concentration was associated with the increased risk of IBD visits from lag $2-$ lag3 days in the single-pollutant model $(\mathrm{RR}=1.037,95 \% \mathrm{Cl}$ : 1.005-1.070, lag 2, 3 day) (Table S1). Subgroup analyses showed that the effect of $\mathrm{PM}_{2.5}$ exposure remained significant in ulcerative colitis visits ( $\mathrm{RR}=1.079,95 \% \mathrm{Cl}$ : $1.023-1.138$, lag 3 day), and warm season subgroups ( $R R=1.104,95 \% C l: 1.032-1.181$, lag 2 day) (Fig. 4, Table S2 and Table S3).

\subsection{2. $\mathrm{O}_{3}$ effects}

Figure 2 and Fig. 3 illustrates that per $10 \mu \mathrm{g} / \mathrm{m}^{3}$ increase in $\mathrm{O}_{3}$ concentration was associated with the increased risk of IBD visits at lag3 day ( $R R=1.020,95 \% \mathrm{Cl}: 1.002-1.038$, lag 3 day) (Table S1). For the subgroup analyses, the effect of $\mathrm{O}_{3}$ exposure remained significant in ulcerative colitis visits $(\mathrm{RR}=1.031$, $95 \% \mathrm{Cl}: 1.002-1.061$, lag 3 day). Besides, the effect of $\mathrm{O}_{3}$ exposure were significant in warm season 
subgroups at lag2 and lag5 day $(\mathrm{RR}=1.023,95 \% \mathrm{Cl}$ : $1.002-1.044$, lag 2 day $)(\mathrm{RR}=1.036,95 \% \mathrm{Cl}$ : $1.004-$ 1.069, lag 5 day) (Fig. 4, Table S2 and Table S3).

\subsection{3. $\mathrm{CO}$ effects}

Figure 2 and Fig. 3 suggests that per $0.1 \mathrm{mg} / \mathrm{m}^{3}$ increase in CO concentration was associated with the increased risk of IBD visits. ( $R R=1.036,95 \% \mathrm{Cl}: 1.003-1.071$, lag 2 day) (Table S1). After stratifying by classification of diseases and season, the associations remained significant in ulcerative colitis (RR = $1.059,95 \% \mathrm{Cl}: 1.001-1.120$, lag 3 day), and warm season subgroups ( $\mathrm{RR}=1.071,95 \% \mathrm{Cl}$ : $1.012-1.133$, lag 2 day) on the exposure to CO (Fig. 4, Table S2 and Table S3).

\subsubsection{Sensitivity analysis}

In the sensitivity analyses, there was no substantial change in the results when changing the degrees of freedom (5-9 df) in the ns function of time. The results suggest that the model fitted well and results were robust (Fig. S1).

\section{Discussion}

With the increased number of residential population and motor vehicles, air pollution in Hefei is becoming more and more serious. In this study, we found that exposure to $\mathrm{PM}_{2.5}, \mathrm{O}_{3}$ and $\mathrm{CO}$ were significantly linked with increased risks of IBD visits. In addition, seasonal variation also impacted the risk of IBD visits. When classifying IBD by disease type, $\mathrm{PM}_{2.5}, \mathrm{O}_{3}$ and $\mathrm{CO}$ had a greater impact on the risk of ulcerative colitis visits than Crohn's disease visits.

The results of this study suggested that $\mathrm{PM}_{2.5}$ exposure led to an increased IBD visits. Previous studies suggested $\mathrm{PM}_{2.5}$ exposure contribute to an increased risk of many gastrointestinal diseases, including IBD (Salim et al. 2014), intestinal infection, gastrointestinal hemorrhage (Gu et al. 2020) and nonalcoholic fatty liver disease (Xu et al. 2019). Some recent studies have reported exposure to particulate matter significantly altered the composition of gut microbiota in humans or animal models (Mutlu et al. 2018; Mutlu et al. 2011). Kish L et al. illustrated that ingested pollutant particles altered gut microbiota composition and function (Kish et al. 2013). Mutlu EA et al. found that upon ingestion of particulate matter, there was an increased small intestinal permeability that was accompanied with an inflammatory response (Mutlu et al. 2018). They further showed that particulate matter induced barrier disruptions were linked to free radical oxygen species (ROS) produced by epithelial cells. In addition, animal model studies suggested that subchronic exposure to concentrated ambient $\mathrm{PM}_{2.5}$ perturbed gut microbiota as well as metabolic profiles (Ran et al. 2021). Therefore, all these findings suggest that gut exposure to $\mathrm{PM}_{2.5}$ may play a pathogenic role in contributing to IBD through disruptions in the epithelial barrier and gut microbiota.

In this study, we found that $\mathrm{O}_{3}$ exposure was associated with an increased risk of IBD visits. It is well known that $\mathrm{O}_{3}$ is one of the most toxic components of the photochemical air pollution mixtures. Many 
epidemiological surveys have shown that exposure to ozone air pollution relates to lung carcinogenesis (Valavanidis et al. 2013), chronic obstructive pulmonary disease (Wiegman et al. 2020), and cardiovascular disease (Rich et al. 2018), mainly through reactive oxygen species (ROS). In addition to inducing diseases in the respiratory and cardiovascular systems, increased ROS generation also contribute to the major pathogenesis and progression of digestive disorders such as IBD (Tian et al. 2017). Himuro $\mathrm{H}$ et al. showed that that intrarectal administration of ozone gas induces transient epithelial cell damage caused particularly by the impairment of DNA replication and cell cycle pathways (Himuro 2018). It is concluded that $\mathrm{O}_{3}$ may causes damage to intestinal epithelium through ROS, thus leading to IBD. Interestingly, $\mathrm{O}_{3}$ has been applied in the field of alternative medicine, particularly in some European countries, for the treatment of IBD (Himuro 2018). Guven A et al. showed that through animal studies, ozone treatment significantly reduced the severity of enterocolitis by modulating antioxidative defense and antiinflammatory protection (Guven et al. 2009). A possible explanation for this might be that different concentrations of $\mathrm{O}_{3}$ have different effects on intestinal. $\mathrm{O}_{3}$ can be very deleterious for the whole organism, however, low-dose $\mathrm{O}_{3}$ that well calibrated against the potent antioxidant capacity of blood can trigger several useful biochemical mechanisms and reactivate the antioxidant system (Bocci et al. 2009), and consequently play a role in the treatment of intestinal diseases. Another possible explanation is that the $\mathrm{O}_{3}$ in our study is industrial ozone produced from air, while the therapeutic effect is medical ozone which is purer than the former. $\mathrm{O}_{3}$ in the environment is unstable, it can react with other air pollutants to produce new compounds (Smith et al. 2016). Therefore, the effect of $\mathrm{O}_{3}$ exposure should be interpreted with caution. The mechanism of $\mathrm{O}_{3}$ in IBD is still worthy of further investigation.

This study reported a positive association between $\mathrm{CO}$ exposure and the risk of IBD visits, which is also supported by previous epidemiological studies (Ananthakrishnan et al. 2018). One study demonstrated, in a population-based cohort and in a replication cohort, that acute rises in the levels of $\mathrm{CO}$ is modestly associated with visits to the emergency department for nonspecific abdominal pain in young women (Kaplan et al. 2012). CO is a major product of the incomplete combustion of carbon and carboncontaining compounds, which avidly binds to hemoglobin with a higher affinity than oxygen and forms carboxyhemoglobin, resulting in interference with the oxygen-carrying capacity of the blood and consequent tissue hypoxia. Some studies have revealed that the poor mucosal healing, refractory inflammatory ulcerations and damage in the IBD intestine could depend on microvascular dysfunction, resulting in diminished vasodilatory capacity and tissue hypoperfusion in the IBD gut (Papa et al. 2008). Zhang $X$ et al. found decreased microvascular endothelial function in relation to increases in short-term exposure to $\mathrm{CO}$ air pollution (Zhang et al. 2016). These studies suggested that $\mathrm{CO}$ may play a role in the pathogenesis of IBD by affecting microvascular function. However, many studies have shown that CO inhibits the development of intestinal inflammation and promotes intestinal (Katada et al. 2015; Onyiah et al. 2014; Zhang et al. 2015). The cause of this phenomenon is the same as the $\mathrm{O}_{3}$ explanation, which is caused by different concentrations and different purity of $\mathrm{CO}$. In conclusion, it is certain that $\mathrm{CO}$, as an air pollutant, has a significant correlation with the incidence of IBD, but when carbon monoxide is produced internally; it may have an inhibitory effect on IBD. 
Seasonal stratification analysis showed that the effects of air pollutants and IBD visits were more pronounced in warm seasons. A number of mechanisms could explain the interaction between air pollutants and high temperature on IBD. Firstly, on a biological level, high temperatures may enhance the toxicity of air pollutants by altering their entry, distribution, and processing in the body (Gordon 2003). Air pollutants and high temperatures may multiply their effects by acting on the same pathophysiological pathways. For example, $\mathrm{PM}_{2.5}, \mathrm{O}_{3}, \mathrm{CO}$, and high temperature are all associated with short-term deficits in cardiovascular disease (Tan et al. 2019). When classified by disease types, Crohn's disease is more sensitive to air pollution. We found that there were studies showed that smoking was bad for the progression of Crohn's disease, but it was good for the progression of ulcerative colitis (BreuerKatschinski et al. 1996; Karczewski et al. 2014). There seems to be a link between Crohn's disease being more sensitive to environmental pollution, however, the specific connection and mechanism are still unclear and need to be further explored.

The study has several strengths. First, to our knowledge, this was the first study to examine the relationship between air pollution exposure and the risk of IBD visits in Hefei, China. Second, compared with the traditional model, we used DLNM to explore the relationships among exposure, lag effect and IBD visits comprehensively. Finally, we explored whether the effects of air pollution exposure on the risk of IBD visits were affected by season or disease type. The limitations of this study are as follows: on the one hand, the sample size is not large enough to analyze the data, so it is necessary to expand the sample size for further research; and on the other hand, the data in this study came from fixed air monitoring stations; therefore, compared with Hefei area, there were fewer monitoring stations, so it could not fully represent the pollutant exposure level in Hefei. More research is needed to verify our findings and investigate potential mechanisms.

\section{Conclusion}

Air pollution exposure could elevate the risk of IBD visits, especially in warm seasons. The effects on Crohn's disease are more pronounced than the effects on ulcerative colitis. The findings indicated that it is necessary to establish a complete environmental monitoring and early warning system to control and prevent IBD onset.

\section{Declarations}

Ethics approval and consent to participate: Applicable

Consent for publication: Not Applicable

Availability of data and materials Data sharing is not applicable to this article as no datasets were generated or analysed during the current study.

Competing interests The authors declare that they have no competing interests. 
Funding information This work was supported by the Research Foundation of Anhui Medical University (No. 2019xkj133).

\section{Authors' contributions}

All authors contributed to the study conception and design. Material preparation, data collection and analysis were performed by [Siwen Ding], [Shu Sun]. The first draft of the manuscript was written by [Siwen Ding]. The manuscript was reviewed and edited by [Rui Ding], [Shasha Song], [Yi Cao]. All authors commented on previous versions of the manuscript. All authors read and approved the final manuscript. [Lijiu Zhang] is the corresponding author and acts on behalf of all authors to ensure the accuracy or completeness of any part of the work.

\section{References}

1. Ananthakrishnan AN, Bernstein CN, Iliopoulos D, Macpherson A, Neurath MF, Ali R, Vavricka SR, Fiocchi C (2018) Environmental triggers in IBD: A review of progress and evidence. Nat Rev Gastroenterol Hepatol 15(1):39-49

2. Ananthakrishnan AN, McGinley EL, Binion DG, Saeian K (2011) Ambient air pollution correlates with hospitalizations for inflammatory bowel disease: An ecologic analysis. Inflamm Bowel Dis 17(5):1138-1145

3. Bernal JL, Cummins S, Gasparrini A (2017) Interrupted time series regression for the evaluation of public health interventions: A tutorial. Int J Epidemiol 46(1):348-355

4. Bernstein CN, Burchill C, Targownik LE, Singh H, Roos LL (2019) Events within the first year of life, but not the neonatal period, affect risk for later development of inflammatory bowel diseases. Gastroenterology 156(8):2190-2197.e10

5. Bhaskaran K, Gasparrini A, Hajat S, Smeeth L, Armstrong B (2013) Time series regression studies in environmental epidemiology. Int J Epidemiol 42(4):1187-1195

6. Bocci V, Borrelli E, Travagli V, Zanardi I (2009) The ozone paradox: Ozone is a strong oxidant as well as a medical drug. Med Res Rev 29(4):646-682

7. Breuer-Katschinski BD, Holländer N, Goebell H (1996) Effect of cigarette smoking on the course of Crohn's disease. Eur J Gastroenterol Hepatol 8(3):225-228

8. Brugha R, Grigg J (2014) Urban air pollution and respiratory infections. Paediatr Respir Rev 15(2):194-199

9. Chen P, Zhou G, Lin J, Li L, Zeng Z, Chen M, Zhang S (2020) Serum biomarkers for inflammatory bowel disease. Front Med (Lausanne) 7:123

10. Cheng H, Zhu F, Lei R, Shen C, Liu J, Yang M, Ding R, Cao J (2019) Associations of ambient PM(2.5) and $\mathrm{O}(3)$ with cardiovascular mortality: A time-series study in Hefei, China. Int J Biometeorol 63(10):1437-1447 
11. Chun H, Leung C, Wen SW, McDonald J, Shin HH (2020) Maternal exposure to air pollution and risk of autism in children: A systematic review and meta-analysis. Environ Pollut 256:113307

12. Flynn S, Eisenstein S (2019) Inflammatory bowel disease presentation and diagnosis. Surg Clin North Am 99(6):1051-1062

13. Gasparrini A (2014) Modeling exposure-lag-response associations with distributed lag non-linear models. Stat Med 33(5):881-899

14. Gordon CJ (2003) Role of environmental stress in the physiological response to chemical toxicants. Environ Res 92(1):1-7

15. Goyette P, Labbé C, Trinh TT, Xavier RJ, Rioux JD (2007) Molecular pathogenesis of inflammatory bowel disease: Genotypes, phenotypes and personalized medicine. Ann Med 39(3):177-199

16. Gu J, Shi Y, Zhu Y, Chen N, Wang H, Zhang Z, Chen T (2020) Ambient air pollution and cause-specific risk of hospital admission in China: A nationwide time-series study. Plos Medicine 17(8):e1003188

17. Guven A, Gundogdu G, Vurucu S, Uysal B, Oztas E, Ozturk H, Korkmaz A (2009) Medical ozone therapy reduces oxidative stress and intestinal damage in an experimental model of necrotizing enterocolitis in neonatal rats. J Pediatr Surg 44(9):1730-1735

18. Himuro H (2018) The Effect of Ozone on Colonic Epithelial Cells. Kurume Med J 64(4):75-81

19. Huang K, Ding K, Yang XJ, Hu CY, Jiang W, Hua XG, Liu J, Cao JY, Zhang T, Kan XH, Zhang XJ (2020) Association between short-term exposure to ambient air pollutants and the risk of tuberculosis outpatient visits: A time-series study in Hefei, China. Environ Res 184:109343

20. Kaplan GG (2015) The global burden of IBD: From 2015 to 2025. Nat Rev Gastroenterol Hepatol 12(12):720-727

21. Kaplan GG, Hubbard J, Korzenik J, Sands BE, Panaccione R, Ghosh S, Wheeler AJ, Villeneuve PJ (2010) The inflammatory bowel diseases and ambient air pollution: A novel association. Am J Gastroenterol 105(11):2412-2419

22. Kaplan GG, Szyszkowicz M, Fichna J, Rowe BH, Porada E, Vincent R, Madsen K, Ghosh S, Storr M (2012) Non-specific abdominal pain and air pollution: A novel association. PLoS One 7(10):e47669

23. Karczewski J, Poniedziałek B, Rzymski P, Rychlewska-Hańczewska A, Adamski Z, Wiktorowicz K (2014) The effect of cigarette smoking on the clinical course of inflammatory bowel disease. Prz Gastroenterol 9(3):153-159

24. Katada K, Takagi T, Uchiyama K, Naito Y (2015) Therapeutic roles of carbon monoxide in intestinal ischemia-reperfusion injury. J Gastroenterol Hepatol 30(Suppl 1):46-52

25. Khreis H, Kelly C, Tate J, Parslow R, Lucas K, Nieuwenhuijsen M (2017) Exposure to traffic-related air pollution and risk of development of childhood asthma: A systematic review and meta-analysis. Environ Int 100:1-31

26. Kim H, Lee JT (2019) On inferences about lag effects using lag models in air pollution time-series studies. Environ Res 171:134-144 
27. Kish L, Hotte N, Kaplan GG, Vincent R, Tso R, Gänzle M, Rioux KP, Thiesen A, Barkema HW, Wine E, Madsen KL (2013) Environmental particulate matter induces murine intestinal inflammatory responses and alters the gut microbiome. PLoS One 8(4):e62220

28. Mutlu EA, Comba IY, Cho T, Engen PA, Yazıcı C, Soberanes S, Hamanaka RB, Niğdelioğlu R, Meliton AY, Ghio AJ, Budinger G, Mutlu GM (2018) Inhalational exposure to particulate matter air pollution alters the composition of the gut microbiome. Environ Pollut 240:817-830

29. Mutlu EA, Engen PA, Soberanes S, Urich D, Forsyth CB, Nigdelioglu R, Chiarella SE, Radigan KA, Gonzalez A, Jakate S, Keshavarzian A, Budinger GR, Mutlu GM (2011) Particulate matter air pollution causes oxidant-mediated increase in gut permeability in mice. Particle Fibre Toxicology 8:19

30. Onyiah JC, Sheikh SZ, Maharshak N, Otterbein LE, Plevy SE (2014) Heme oxygenase-1 and carbon monoxide regulate intestinal homeostasis and mucosal immune responses to the enteric microbiota. Gut Microbes 5(2):220-224

31. Papa A, Scaldaferri F, Danese S, Guglielmo S, Roberto I, Bonizzi M, Mocci G, Felice C, Ricci C, Andrisani G, Fedeli G, Gasbarrini G, Gasbarrini A (2008) Vascular involvement in inflammatory bowel disease: Pathogenesis and clinical aspects. Dig Dis 26(2):149-155

32. Ran Z, An Y, Zhou J, Yang J, Zhang Y, Yang J, Wang L, Li X, Lu D, Zhong J, Song H, Qin X, Li R (2021) Subchronic exposure to concentrated ambient $\mathrm{PM}_{2.5}$ perturbs gut and lung microbiota as well as metabolic profiles in mice. Environ Pollut 272:115987

33. Rich DQ, Balmes JR, Frampton MW, Zareba W, Stark P, Arjomandi M, Hazucha MJ, Costantini MG, Ganz P, Hollenbeck-Pringle D, Dagincourt N, Bromberg PA (2018) Cardiovascular function and ozone exposure: The Multicenter Ozone Study in oldEr Subjects (MOSES). Environ Int 119:193-202

34. Sairenji T, Collins KL, Evans DV (2017) An Update on Inflammatory Bowel Disease. Prim Care 44(4):673-692

35. Salim SY, Kaplan GG, Madsen KL (2014) Air pollution effects on the gut microbiota: A link between exposure and inflammatory disease. Gut Microbes 5(2):215-219

36. Sies H (1997) Oxidative stress: Oxidants and antioxidants. Exp Physiol 82(2):291-295

37. Smith GS, Van Den Eeden SK, Garcia C, Shan J, Baxter R, Herring AH, Richardson DB, Van Rie A, Emch M, Gammon MD (2016) Air pollution and pulmonary tuberculosis: A nested Case-Control study among members of a northern california health plan. Environ Health Perspect 124(6):761-768

38. Tan F, Wang W, Qi S, Kan H, Yu X, Liu Y, Wu D, Xu B, Meng F, Liu S (2019) Air pollutants and outpatient visits for cardiovascular disease in a severe haze-fog city: Shijiazhuang, China. Bmc Public Health 19(1):1366

39. Tian T, Wang Z, Zhang J (2017) Pathomechanisms of oxidative stress in inflammatory bowel disease and potential antioxidant therapies. Oxidative Medicine and Cellular Longevity, 2017: 4535194

40. Valavanidis A, Vlachogianni T, Fiotakis K, Loridas S (2013) Pulmonary oxidative stress, inflammation and cancer: Respirable particulate matter, fibrous dusts and ozone as major causes of lung 
carcinogenesis through reactive oxygen species mechanisms. Int J Environ Res Public Health 10(9):3886-3907

41. Wiegman CH, Li F, Ryffel B, Togbe D, Chung KF (2020) Oxidative stress in Ozone-Induced chronic lung inflammation and emphysema: A facet of chronic obstructive pulmonary disease. Frontiers in Immunology, 11: 1957

42. Xu MX, Ge CX, Qin YT, Gu TT, Lou DS, Li Q, Hu LF, Feng J, Huang P, Tan J (2019) Prolonged $\mathrm{PM}_{2.5}$ exposure elevates risk of oxidative stress-driven nonalcoholic fatty liver disease by triggering increase of dyslipidemia. Free Radic Biol Med 130:542-556

43. Zhang S, Zheng S, Wang X, Shi Q, Wang X, Yuan S, Wang G, Ji Z (2015) Carbon Monoxide-Releasing molecule-2 reduces intestinal epithelial Tight-Junction damage and mortality in septic rats. PLoS One 10(12):e0145988

44. Zhang X, Staimer N, Tjoa T, Gillen DL, Schauer JJ, Shafer MM, Hasheminassab S, Pakbin P, Longhurst J, Sioutas C, Delfino RJ (2016) Associations between microvascular function and shortterm exposure to traffic-related air pollution and particulate matter oxidative potential. Environ Health 15(1):81

\section{Tables}

Due to technical limitations, table 1,2 is only available as a download in the Supplemental Files section.

\section{Figures}



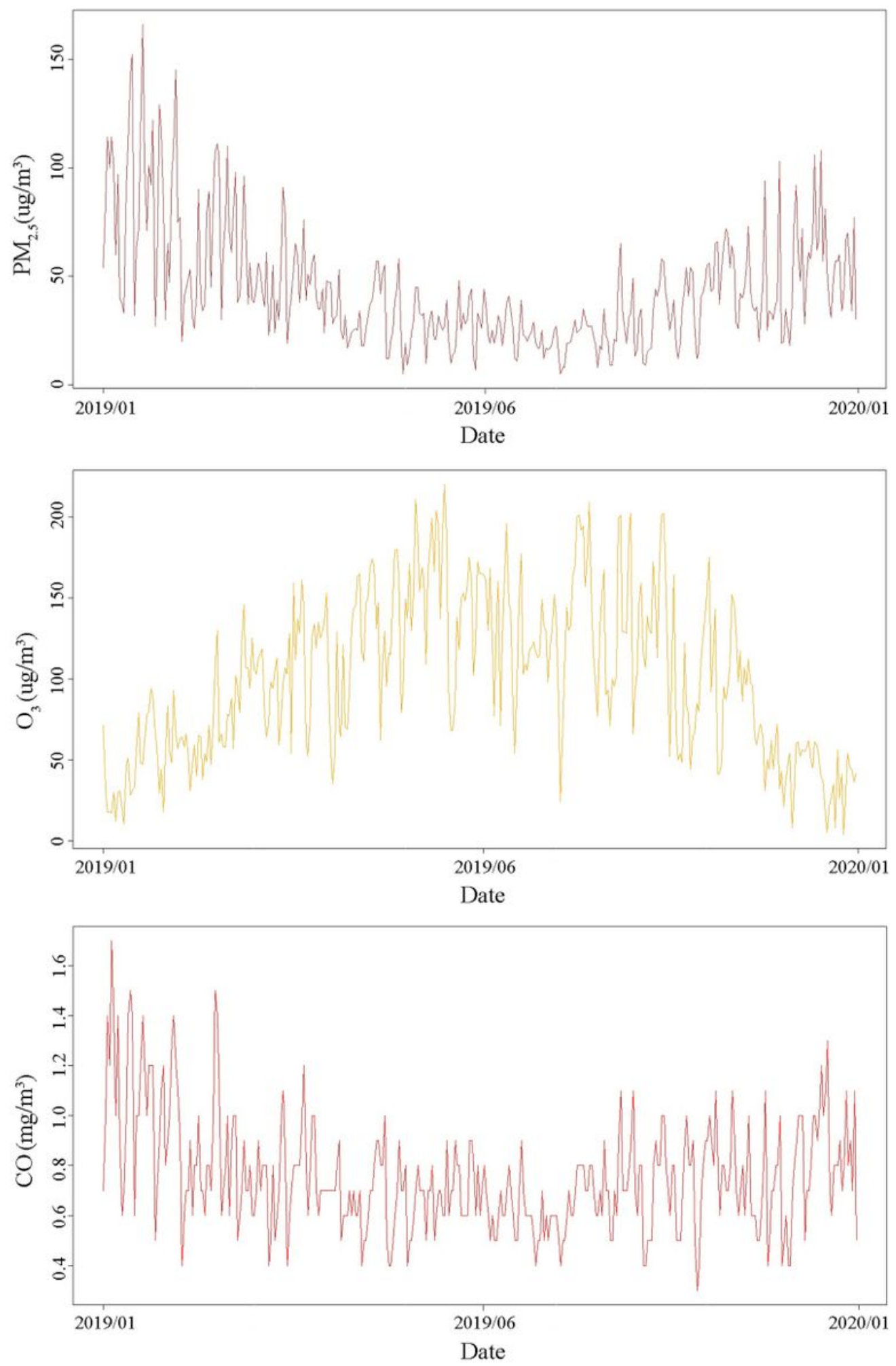

Figure 1

The time series of air pollutants in Hefei, China during 2019.01-2019.12. 

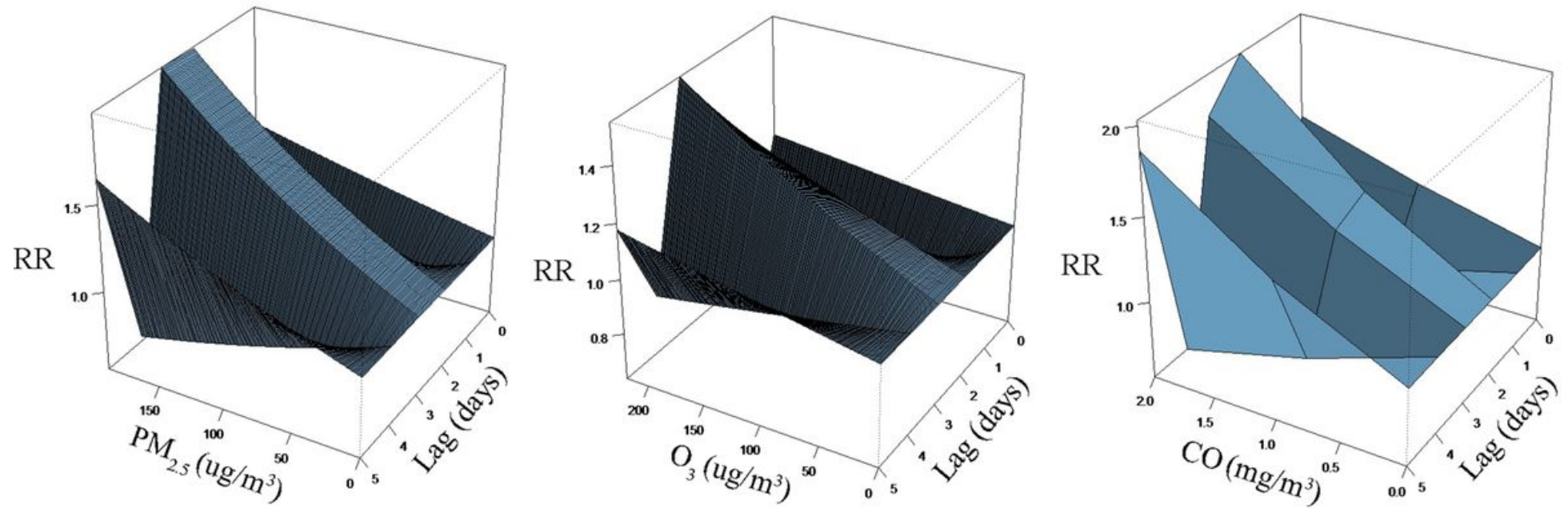

Figure 2

The three dimensional (3D) plots of estimated relative risks (RR) for air pollutants associated with inflammatory bowel disease.
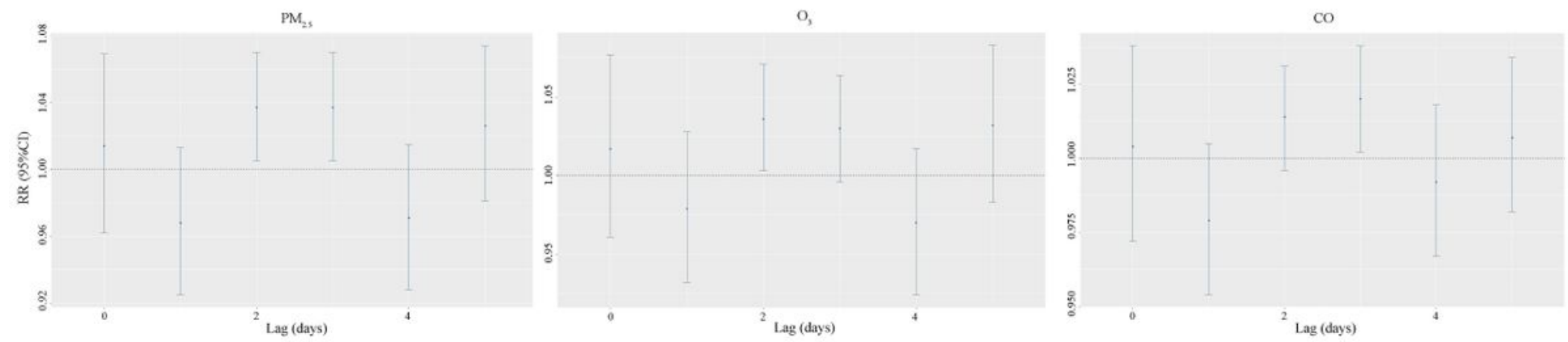

Figure 3

Lag-specific relative risk (RR) of inflammatory bowel disease associated with air pollutants exposure.
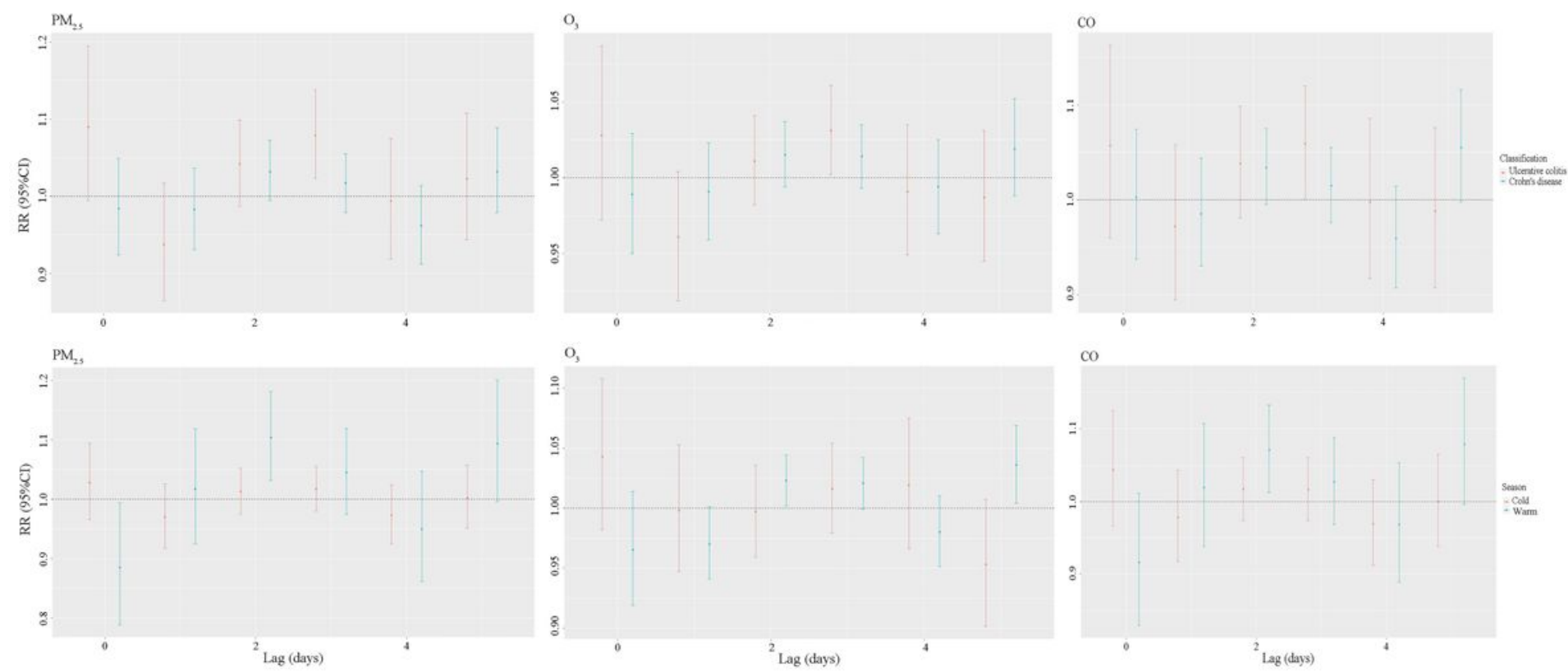
Figure 4

Lag-specific relative risk (RR) of inflammatory bowel disease associated with air pollutants exposure stratified by classification and season.

\section{Supplementary Files}

This is a list of supplementary files associated with this preprint. Click to download.

- Fig.S1.jpg

- SupplementaryTables.pdf

- Table.pdf 